\title{
Systolic time intervals in coronary artery disease as indices of left ventricular function: fact or fancy?
}

\author{
M. E. Parker and H. G. Just ${ }^{1}$ \\ with technical assistance of E. Scholl \\ From the III Medizinische Universitätsklinik und Poliklinik, Mainz, Germany
}

Characteristic changes in systolic time intervals have been described in left ventricular failure, and it has been held that patients with coronary artery disease have similar abnormalities in pre-ejection and ejection times as well as in the length of total electromechanical systole. In order to assess the contribution of systolic time intervals to the clinical evaluation of patients with coronary artery disease, correlative studies were made between systolic time intervals and the standard variables of contractility and performance obtained at cardiac catheterization.

$A$ wide spectrum of left ventricular functional disturbance was present in 36 male patients with electrocardiographically and angiographically demonstrable coronary artery disease. While excellent correlations were shown between contractility indices, especially $d p / d t$ max, and ejection fraction and extent of asynergy, systolic time intervals were not reliable indices of ventricular function. It is doubtful whether systolic time intervals are of value in the clinical assessment of coronary artery disease.

The haemodynamic changes in coronary heart disease have been the subject of numerous investigations. It is generally agreed that the first derivative of the pressure pulse $(\mathrm{dp} / \mathrm{dt})$ in man, despite its dependence on multiple variables, can be taken as an index of the contractile state in health and in disease (Mason, 1969). This, however, as well as other factors relating to left ventricular function - ejection fraction (EF), max. systolic ejection rate (MSER), end-diastolic volume (EDV) - is obtainable only through an invasive procedure and therefore not available to general clinical assessment. It would be useful if within the classical approach of Osler observation, palpation, auscultation, contemplation - an easily and externally measured variable could be shown to correlate well with the more definitive intracardiac measurements of ventricular performance.

It has been suggested that one such variable in coronary artery disease might be obtained by the determination of systolic time intervals through recording of the carotid pressure pulse simultaneously with the phonocardiogram and apex cardiogram (McConahay, Martin, and Cheitlin, 1972; Garrard, Weissler, and Dodge, 1970; Aronow, Bowyer, and Received 1o October 1973.

1 With support of the Alexander von Humboldt-Foundation.
Kaplan, 1971). That changes in cardiac contraction influence the length of mechanical systole is known (Metzger et al., 1970). At what point and through what mechanisms this influence is exerted remains largely unexplained. Similarly the role of relaxation, especially its relation to the factors determining the duration of systole, is not clear.

A group of patients with known coronary artery disease and presenting with a wide spectrum of left ventricular functional disturbance at the time of routine and preoperative evaluation through cardiac catheterization offers an opportunity for correlative observations in this regard. The purpose of this study was to compare velocity-related indices of left ventricular function with ventricular performance as defined angiographically and to examine the relation of these variables to systolic time intervals in ischaemic heart disease. These alterations as determined at catheterization will be discussed with respect to one another and with regard to their extension to bedside examination in coronary heart disease.

\section{Subjects and methods}

Thirty-six male patients with coronary heart disease as defined clinically by classical angina pectoris and electrocardiographically by the presence of changes consistent 
with either previous myocardial infarction or stressinduced ischaemia were studied by right and left heart catheterization with selective coronary and left ventricular angiography. Their ages ranged from 35 to 62 , with a mean of 52 years. A total of 33 infarcts was documented, 7 patients having more than I ( 5 patients in this group having double and 2 patients triple lesions). Sixteen posterior wall, 13 anterior, and 4 mixed infarctions were electrocardiographically present. Twelve patients had severe angina pectoris but no infarction. Patients with manifest left ventricular insufficiency, auscultatory evidence of mitral regurgitation, or radiographically demonstrable aneurysm were excluded from the study, since in these cases the isovolumetric requirements for evaluation of contractility by means of velocity related indices are not fulfilled. All patients were in sinus rhythm. One case of left bundle-branch block and three of incomplete right bundle-branch block were observed, the velocity indices in none of these cases significantly influencing the mean findings for the group as a whole. The therapeutic regimen for each patient, consisting primarily of nitroglycerin preparations, was continued for up to 24 hours before the study. Propranolol and related drugs, where chronically used, were discontinued for at least 7 days preceding catheterization. It should be noted that a ventricular diastolic gallop had been noted in 16 patients at varying times during precatheterization examination. While not interpreted as overt insufficiency or accompanied by other objective evidence of decompensation (neck vein distension, $x$-ray abnormalities), this had led in some cases to the administration of digitalis, which was continued for up to 24 hours before the procedure. It is important to mention that blood volume, changes in which may have occurred under digitalis and diuresis, was not measured at the time of catheterization.

Intracardiac pressures were measured with the Statham micromanometer SF I or P 866 with simultaneous recording on the Hellige multichannel console of the electrocardiogram, the left ventricular pressure pulse, and, through an electronic differentiating circuit, its first derivative (dp/dt). Measurements of left ventricular enddiastolic pressure, $\mathrm{dp} / \mathrm{dt} \max$, and related contractile indices were taken from high speed $(200 \mathrm{~mm} / \mathrm{sec})$ photographic paper recordings of left ventricular pressure. In each case calculations were made from at least five separate systolic contractions during the post-expiratory resting phase of respiration.

Systolic time intervals were measured, in all cases before angiography, from simultaneous recordings of the electrocardiogram and the aortic pressure pulse as registered by the catheter tip micromanometer. The following phases of the cardiac cycle were measured directly: (I) total electromechanical systole (QA2) from the onset of the QRS complex to the trough of the incisura of the aortic pulse; (2) left ventricular ejection time (LVET) from the beginning of the aortic upstroke to the incisura; and (3) the pre-ejection period (PEP), taken as the difference between the QA2 interval and LVET (Fig. I). Heart rate was calculated by dividing the average RR interval on 5 consecutive cycles with regular rhythm, each read to the nearest millisecond, into 60 . The regression equation relating heart rate to systolic

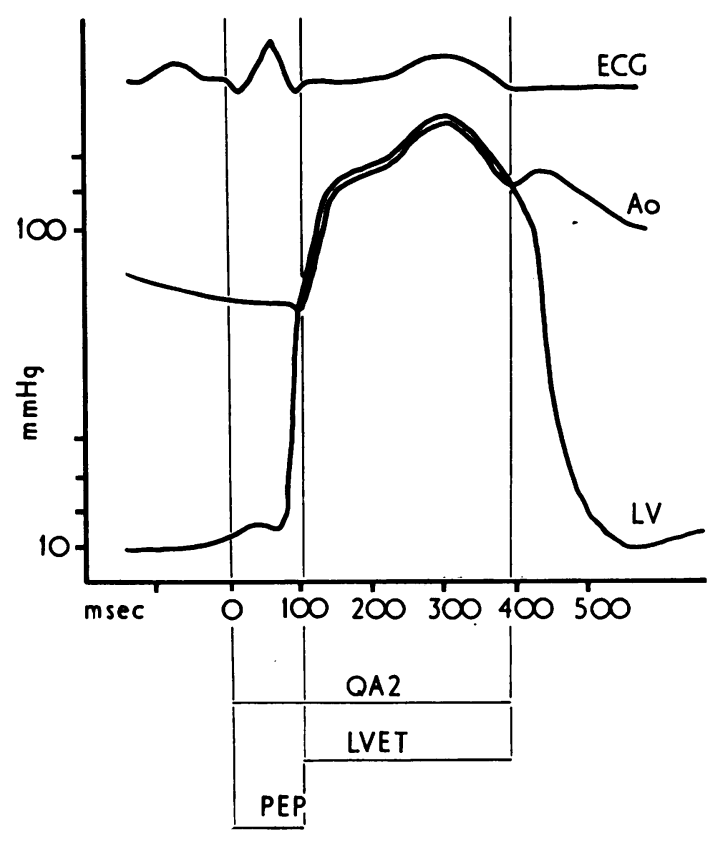

FIG. I High-fidelity intracardiac pressure curves obtained from the left ventricle and aorta with the micromanometer, showing measurement of systolic time intervals.

time intervals has been derived by Weissler, Harris, and Schoenfeld (1968). In addition to expression of the absolute values for each interval, the magnitude of change in the variables PEP, LVET, and QA2 was obtained by subtracting the observed value from the mean normal value at the same heart rate and expressed as an increase or decrease from zero in milliseconds.

From extrapolation to the left ventricular pressure curve with simultaneous registration of the first derivative of the pressure pulse $(\mathrm{dp} / \mathrm{dt})$ the following additional measurements were made: (I) isovolumic contraction time (ICT) derived as the difference between the PEP and the time from the onset of the QRS complex to the upstroke of both the left ventricular pressure pulse and its electronically differentiated first derivative; (2) Q-dp/dt max and Q-dp/dt relax; (3) from the above data the quotients LVET/PEP and LVET/ICT were derived. Care was taken to ensure that the heart rate was the same as that registered during the aortic pulse recording; in most cases this was obtained by virtue of the left ventricle-aorta pullback manoeuvre.

Ventricular injection for angiocardiography was made in the right anterior oblique (RAO) projection with the patient at $30^{\circ}$ rotation or that which ensured projection of the longest axis of the left ventricle. After injection of 40 to $70 \mathrm{ml}$ of Angiografin single-plane cineangiograms were made at 80 frames per second. In 23 of the 36 patients ejection fraction (EF) could be calculated from 
the angiographic series according to the methods of Dodge et al. (1960). For this group asynergy was derived from the single plane angiocardiograms as a percentage estimate of that portion of the ventricular surface which did not contribute to contraction,.

Selective right and left coronary angiography followed, using the techniques of Sones and/or Judkins, with hand injection of 5 to $10 \mathrm{ml}$ of Angiografin and $35 \mathrm{~mm}$ cineangiography at 64 frames per second.

\section{Results}

Left ventricular function as determined by isovolumic velocity-related contractility indices and quantitative angiographic variables were used as a gauge with which to compare systolic time intervals.

The haemodynamic variables and contractility data are presented in Table $I$, including ejection fraction (EF) and percentage asynergy, as derived angiographically.

\section{Contractility}

The mean values for $\mathrm{dp} / \mathrm{dt} \max$ and $\mathrm{dp} / \mathrm{dt}$ relax did not show significant deviations from the norm as calculated for the group as a whole. Extreme variations

TABLE I Haemodynamic and contractility variables

\begin{tabular}{|c|c|c|c|c|c|c|c|c|c|c|c|c|}
\hline $\begin{array}{l}\text { Case } \\
\text { No. }\end{array}$ & $H R$ & Ao $(n$ & ${ }_{d}^{m m} H$ & & $\begin{array}{l}L V E D P \\
(m m H g)\end{array}$ & $\begin{array}{l}d p / d t \text { max } \\
(m m H g / s e c)\end{array}$ & $\begin{array}{l}d p / d t \text { relax } \\
(m m H g / s e c)\end{array}$ & $\begin{array}{l}t-d p / d t \\
\max \\
(m s e c)\end{array}$ & $\begin{array}{l}d p / d t \\
\max / I P \\
\left(s e c^{-1}\right)\end{array}$ & $E F$ & $\begin{array}{l}\text { Asyn. } \\
(\%)\end{array}$ & $\begin{array}{l}M S E R \\
(\mathrm{ml} / \mathrm{sec})\end{array}$ \\
\hline I & 78 & 175 & 901 & 120 & 13.0 & 1430 & 1215 & 70 & $23 \cdot 8$ & I0.34 & 50 & 125 \\
\hline 2 & $70^{\star}$ & 108 & 67 & 83 & 6.5 & $I 400$ & I750 & IIO & 23.0 & & & 254 \\
\hline 3 & 79 & 120 & 70 & 95 & 12.0 & 1440 & 1248 & 76 & $23 \cdot 1$ & & & I 89 \\
\hline 4 & 96 & 95 & 60 & 72 & $12 \cdot 0$ & 910 & 700 & 75 & $25 \cdot 3$ & $12 \cdot 44$ & 60 & 184 \\
\hline 5 & 77 & 93 & 63 & 76 & $29 \cdot 0$ & 830 & 934 & 70 & 28.6 & $1 \mathrm{I} \cdot 36$ & 10 & I43 \\
\hline 6 & 92 & 108 & 74 & 83 & $26 \cdot 0$ & 1030 & 772 & 70 & $32 \cdot 2$ & & & 79 \\
\hline 7 & $8 I$ & I IO & 70 & 93 & 19.0 & 1330 & 1240 & 70 & $27 \cdot 8$ & 13.80 & 70 & 123 \\
\hline 8 & 62 & 138 & 78 & 100 & $2 I \cdot 0$ & I I60 & 730 & 38 & $20 \cdot 0$ & $22 \cdot 24$ & 35 & 190 \\
\hline 9 & 68 & 120 & 70 & 85 & $12 \cdot 0$ & 1250 & 1300 & 65 & $27 \cdot 2$ & $43 \cdot 00$ & 10 & - \\
\hline Io & 59 & 140 & 80 & 100 & 10.0 & 1710 & 1700 & 70 & $24 \cdot 2$ & & & 307 \\
\hline I I & 90 & I 5 & 70 & 82 & $9 \cdot 0$ & I660 & 1410 & 70 & $29 \cdot 6$ & & & 217 \\
\hline 12 & 72 & 160 & 88 & I05 & 6.0 & 2000 & I7IO & 70 & $28 \cdot 5$ & $47 \cdot 25$ & 0 & - \\
\hline 13 & 56 & 120 & 70 & 85 & 13.0 & 1200 & 1300 & 56 & 25.0 & $27 \cdot 14$ & 25 & 326 \\
\hline I 4 & 80 & 100 & 60 & 70 & II.O & 930 & 930 & 63 & 19.0 & 10.25 & 60 & 120 \\
\hline 15 & 70 & 120 & 70 & 90 & $5 \cdot 0$ & 1160 & 1260 & 80 & 18.0 & $22 \cdot 80$ & 25 & I 39 \\
\hline 16 & 55 & 180 & 75 & II 2 & 10.0 & 2220 & I334 & 180 & $26 \cdot 4$ & & & 225 \\
\hline 17 & 78 & 150 & 80 & 100 & 8.0 & 2560 & 1760 & 58 & $34 \cdot I$ & & & - \\
\hline 18 & 69 & 100 & 60 & 80 & $5 \cdot 0$ & 2190 & 1750 & 50 & $49 \cdot 8$ & 63.00 & 0 & 292 \\
\hline 19 & 103 & 175 & 104 & I30 & 10.0 & 2260 & 1550 & 40 & 39.5 & 63.54 & 0 & 93 \\
\hline 20 & 75 & 140 & 80 & 90 & $2 \cdot 0$ & 2200 & 2300 & 59 & $32 \cdot 4$ & $21 \cdot 50$ & 30 & - \\
\hline 21 & 90 & 120 & 70 & 95 & 13.0 & 1750 & 1700 & 53 & $44 \cdot 5$ & 27.95 & 30 & - \\
\hline 22 & 84 & 136 & 90 & I 10 & 20.0 & 2900 & 2320 & 80 & $48 \cdot 0$ & & & - \\
\hline 23 & 79 & 148 & 74 & 100 & $22 \cdot 0$ & I960 & I668 & 45 & $43 \cdot 8$ & $34 \cdot 48$ & IO & 216 \\
\hline 24 & 80 & 168 & II4 & 130 & $5 \cdot 0$ & I660 & 1800 & 70 & 23.3 & $28 \cdot 24$ & IO & 167 \\
\hline 25 & 72 & 135 & 80 & I IO & 6.0 & 1950 & 1750 & 65 & 26.6 & $46 \cdot 63$ & 10 & 126 \\
\hline 26 & 70 & 130 & 90 & 100 & $8 \cdot 0$ & 1600 & 1600 & 60 & 26.0 & & & II9 \\
\hline 27 & 68 & I I4 & 75 & 87 & $12 \cdot 0$ & I 557 & I I I 2 & 60 & $28 \cdot 3$ & $44 \cdot 80$ & 0 & 280 \\
\hline 28 & 76 & I30 & 74 & 90 & 10.0 & 1496 & I496 & 53 & $30 \cdot 2$ & & & 337 \\
\hline 29 & 89 & 190 & 94 & 128 & 5.0 & 2210 & 2200 & 68 & $26 \cdot 3$ & 40.51 & 0 & - \\
\hline 30 & 67 & 130 & 70 & 100 & 5.0 & 2070 & I810 & 53 & $33 \cdot 7$ & & & 209 \\
\hline $3 I$ & 67 & 160 & 80 & IIO & 8.0 & 1960 & 2300 & 80 & $23 \cdot 3$ & $49 \cdot 79$ & I6 & I74 \\
\hline 32 & 73 & I6o & 80 & I IO & 20.0 & 1700 & 1800 & 63 & $26 \cdot 2$ & & & 139 \\
\hline 33 & 89 & 125 & 75 & 96 & I I 0 & 1600 & 1600 & 58 & $32 \cdot 0$ & 50.42 & 0 & 165 \\
\hline 34 & 75 & 120 & 75 & 92 & $28 \cdot 0$ & 1600 & I550 & 55 & $38 \cdot 0$ & $3 I \cdot 28$ & 0 & - \\
\hline 35 & 68 & 160 & 76 & 100 & $8 \cdot 0$ & I984 & 1526 & 55 & $28 \cdot 4$ & $22 \cdot 55$ & 30 & 224 \\
\hline $\begin{array}{l}36 \\
\text { Mean }\end{array}$ & $\begin{array}{l}55 \\
75.5\end{array}$ & 150 & 65 & $\begin{array}{l}90 \\
97 \cdot I\end{array}$ & $\begin{array}{r}5.0 \\
I I \cdot 8\end{array}$ & 2230 & 1360 & 75 & $37 \cdot 0$ & & & - \\
\hline SD & $\begin{array}{l}75.1 \\
15.1\end{array}$ & & & I5.1 & 6.9 & $\begin{array}{r}1097 \\
484\end{array}$ & $\begin{array}{r}1513 \\
417\end{array}$ & $\begin{array}{l}64 \cdot 8 \\
13 \cdot 4\end{array}$ & $\begin{array}{r}29 \cdot 8 \\
7 \cdot 8\end{array}$ & & & \\
\hline
\end{tabular}

Ao $=$ aortic pressure $. \mathrm{LVEDP}=$ left ventricular end-diastolic pressure

$\mathrm{dp} / \mathrm{dt} \max , \mathrm{t}-\mathrm{dp} / \mathrm{dt} \max ,(\mathrm{dp} / \mathrm{dt} \max ) / \mathrm{IP}=$ velocity related contractility indices of isovolumic contraction time (Krayenbühl, I969).

$\mathrm{dp} / \mathrm{dt}$ relax $=$ maximum velocity of relaxation. $\mathrm{EF}=$ ejection fraction.

Asyn. = area of asynergic contraction in per cent of total ventricular circumference. $M S E R=$ mean systolic rate of ejection. 
in $\mathrm{dp} / \mathrm{dt}$ max were, however, observed in individual cases, and there were significant correlations with cardiac performance as expressed by ejection fraction and extent of asynergic contraction, the relation with EF being direct $(r=0.67, P<0.01)$ and with percentage asynergy inverse $(r=0.53, P<0.01)$. The variables MSER and (dp/dt max)/IP responded similarly. Of note was a decrease in $\mathrm{dp} / \mathrm{dt}$ relax as compared to $\mathrm{dp} / \mathrm{dt} \max$ in 23 patients, well over half the patient group. The degree of significance obtained by comparison of dp/dt relax with EF and asynergy was not improved over that gained from the comparison of $\mathrm{dp} / \mathrm{dt} \max$ with these variables.

\section{Ejection fraction (EF) and asynergy}

An excellent inverse relation $(r=0.78, P<0.01)$ was obtained between calculated ejection fraction and per cent estimate of asynergic contraction.

\section{Systolic time intervals}

The absolute systolic time intervals, with an expression of deviation from the normal regression curve of Weissler et al. (1968), and the quotient LVET/PEP, are presented in Table 2. Fig. 2 illustrates the scatter of values for PEP, LVET, and QA2 about the normal regression slopes for male patients.

While pronounced deviations were present in individual cases, the values for PEP, LVET, and

TABLE 2 Systolic time intervals

\begin{tabular}{|c|c|c|c|c|c|c|c|c|c|}
\hline $\begin{array}{l}\text { Case } \\
\text { No. }\end{array}$ & $H R$ & $\underset{(m s e c)}{Q A 2}$ & $\begin{array}{l}\Delta Q A 2 \\
\left(m \operatorname{mec}^{2}\right)\end{array}$ & $\begin{array}{l}\text { LVET } \\
\text { (msec) }\end{array}$ & $\begin{array}{l}\Delta L V E T \\
\text { (msec) }\end{array}$ & $\begin{array}{l}P E P \\
(m s e c)\end{array}$ & $\begin{array}{l}\triangle P E P \\
(m s e c)\end{array}$ & $\begin{array}{l}I C T \\
\text { (msec) }\end{array}$ & $\begin{array}{l}\text { LVET } \\
\text { (units) }\end{array}$ \\
\hline I & 78 & 425 & +43 & 320 & +40 & 105 & +5 & 85 & $3 \cdot 0$ \\
\hline 2 & 70 & 420 & +21 & 260 & -34 & 160 & +57 & 70 & $1 \cdot 6$ \\
\hline 3 & 79 & 420 & +40 & 290 & $+\mathrm{II}$ & 130 & +30 & 20 & $2 \cdot 2$ \\
\hline 4 & 96 & 360 & +24 & 250 & 0 & IIO & +17 & 90 & $2 \cdot 3$ \\
\hline 5 & 77 & 400 & +16 & 280 & -2 & 120 & +20 & 70 & $2 \cdot 3$ \\
\hline 6 & 92 & 350 & -3 & 240 & -17 & IIO & +16 & 50 & $2 \cdot 2$ \\
\hline 7 & 81 & 345 & -45 & 240 & -35 & 105 & +6 & 90 & $2 \cdot 3$ \\
\hline 8 & 62 & 440 & +24 & 340 & +32 & 100 & -6 & 80 & $3 \cdot 4$ \\
\hline 9 & 68 & 400 & -3 & 290 & -7 & IIO & +6 & 70 & $2 \cdot 6$ \\
\hline I0 & 59 & 420 & -2 & 300 & -13 & 120 & +13 & 80 & 2.5 \\
\hline II & 90 & 320 & -37 & 240 & -20 & 80 & -15 & 80 & $3 \cdot 0$ \\
\hline 12 & 72 & 410 & +15 & 300 & +9 & 90 & -12 & 70 & $3 \cdot 3$ \\
\hline 13 & 56 & 435 & +7 & 350 & +32 & 85 & -24 & 65 & $4 \cdot I$ \\
\hline 14 & 80 & 350 & -28 & 250 & -27 & 100 & $+I$ & 80 & $2 \cdot 5$ \\
\hline I5 & 70 & 400 & $+I$ & 290 & -4 & IIO & +7 & 90 & $2 \cdot 6$ \\
\hline 16 & 55 & 400 & $-3 I$ & 320 & 0 & 80 & -29 & 60 & $4 \cdot 0$ \\
\hline 17 & 78 & 380 & -2 & 290 & +10 & 90 & -10 & 65 & $3 \cdot 2$ \\
\hline 18 & 69 & 500 & +99 & 370 & +74 & 130 & +27 & IIo & $2 \cdot 9$ \\
\hline 19 & 103 & 380 & +50 & 260 & +22 & 120 & +30 & 75 & $2 \cdot 2$ \\
\hline 20 & 75 & 360 & -29 & 280 & -6 & 80 & $-2 I$ & 80 & 3.5 \\
\hline 21 & 90 & 360 & +3 & 270 & +10 & 90 & -5 & 60 & $3 \cdot 8$ \\
\hline 22 & 84 & 420 & +50 & 300 & +30 & 120 & +23 & 105 & 2.5 \\
\hline 23 & 79 & 350 & -30 & 250 & -29 & 100 & 0 & 80 & 2.5 \\
\hline 24 & 80 & 380 & +2 & 270 & -7 & IIO & $+I I$ & 100 & $2 \cdot 4$ \\
\hline 25 & 72 & 370 & -25 & 280 & - II & 100 & -2 & 70 & $2 \cdot 8$ \\
\hline 26 & 70 & 375 & -24 & 275 & - I9 & 100 & -3 & 80 & $2 \cdot 7^{\circ}$ \\
\hline 27 & 68 & 400 & -3 & 320 & +23 & 80 & -24 & 60 & $4 \cdot 0$ \\
\hline 28 & 76 & 370 & -16 & 300 & +16 & 70 & $-3 I$ & 50 & $4 \cdot 3$ \\
\hline 29 & 89 & 360 & $+I$ & 290 & +28 & 70 & -25 & 50 & $4 \cdot I$ \\
\hline 30 & 67 & 380 & -15 & 310 & $+I I$ & 70 & -34 & 55 & $4 \cdot 4$ \\
\hline 31 & 67 & 415 & +10 & 340 & +59 & 75 & -29 & 60 & $4 \cdot 5$ \\
\hline 32 & 73 & 400 & +7 & 318 & +29 & 80 & -22 & 60 & 3.9 \\
\hline 33 & 89 & 400 & $+4 I$ & 310 & +48 & 90 & -5 & 70 & 3.4 \\
\hline 34 & 75 & 360 & -29 & 280 & -6 & 80 & $-2 \mathrm{I}$ & 60 & 3.5 \\
\hline 35 & 68 & 400 & -3 & 280 & -17 & II 5 & $+I I$ & 70 & $2 \cdot 4$ \\
\hline 36 & 55 & 390 & -59 & 300 & -20 & 60 & -49 & 60 & 5.0 \\
\hline
\end{tabular}

$\mathrm{QA2}=$ total duration of systole $; \mathrm{LVET}=$ left ventricular ejection time; $\mathrm{PEP}=$ pre-ejection period; $\mathrm{ICT}=$ isovolumic contraction time; $\triangle \mathrm{QA2}, \triangle \mathrm{PEP}, \Delta \mathrm{LVET}=$ deviation from normal regression curves (Weissler et al., 1968, see text). 

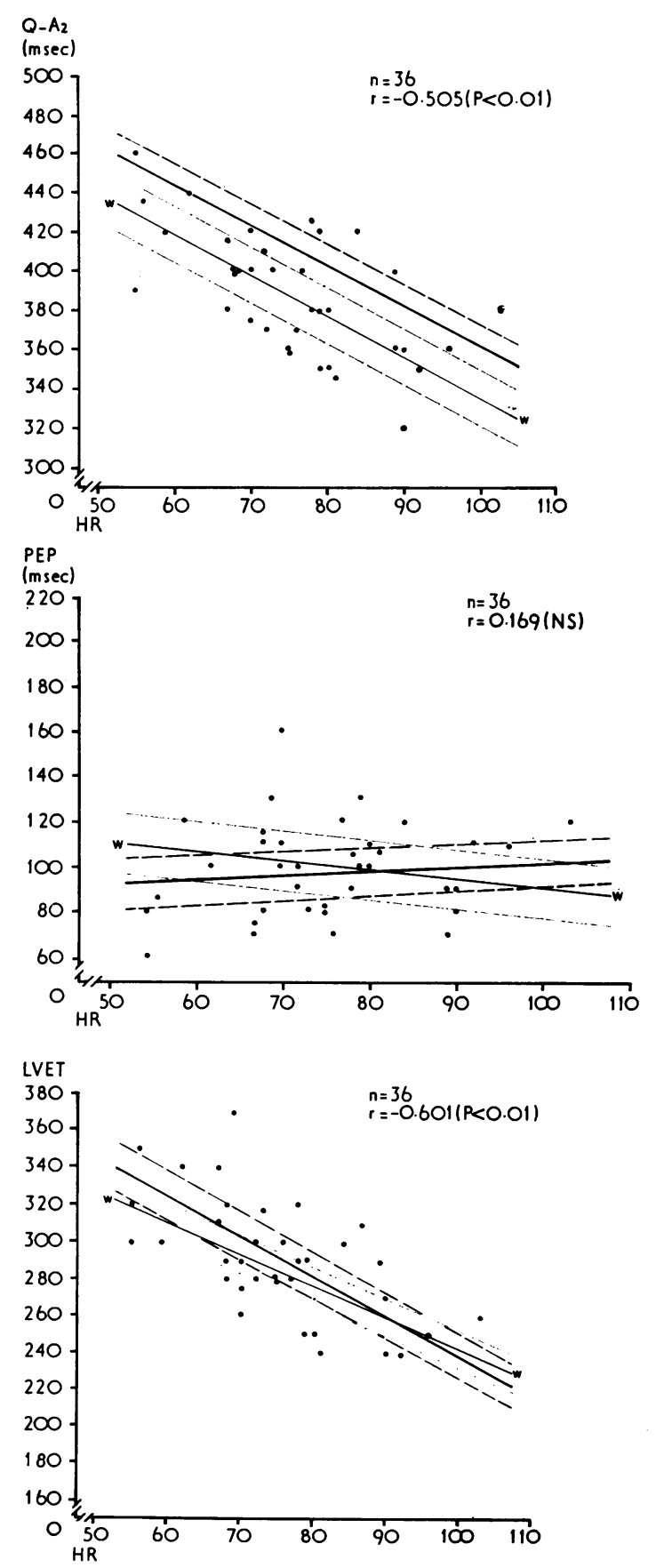

QA2 were distributed in such a manner that no group deviation from the normal could be identified. Indeed, as shown in Fig. 2, the overall distribution of systolic time intervals with regard to heart rate might appear to have been derived from normal controls rather than from a patient group with the extent of myocardial damage known to be present. In contrast to the observations of Blumberger as early as 1942, and of Weissler et al. more recently (I968), and Weissler, Harris, and Schoenfeld (I969), that the pre-ejection period (PEP) is prolonged and left ventricular ejection time (LVET) shortened in heart failure, the PEP and LVET in our patients showed random distribution about the normal regression slopes, even in cases where pathologically raised end-diastolic pressure or clinical evidence might be indicative of a pre-failure state. Similarly, even where extensive three-vessel disease was angiographically demonstrable, the PEP and LVET were scattered over a wide range of values, in contrast to the PEP prolongation and LVET shortening remarked in coronary artery disease by other observers (McConahay et al., 1972).

To assess the relation of pre-ejection and ejection times and total length of systole to parameters of contractility and function, both the absolute values and the deviations in these intervals relative to heart rate ( $\triangle \mathrm{PEP}, \triangle \mathrm{LVET}$, and $\triangle \mathrm{QA2}$ ) were plotted individually against the first derivative of the pressure pulse (dp/dt max), ejection fraction, and asynergy. As might have been expected from the random distribution of absolute values about the normal regression curve, no significant correlations between either these values or change in the systolic intervals relative to $\mathrm{dp} / \mathrm{dt} \max$, ejection fraction, or asynergy were observed (Table 3, Fig. 3).

Similarly unproductive were comparisons of the quotient LVET/PEP to these indices (Fig. 4). This quotient, expressed either as LVET/PEP or the inverse PEP/LVET, has been seen in previous studies (McConahay et al., 1972; Blumberger, 1942) to show characteristic variations in both cardiac insufficiency and in coronary artery disease.

Consideration of the interval ICT did not add to information already gained from the PEP relative to ejection fraction or contractility. ICT tended to vary

FIG. 2 Above, total electromechanical systole ( $Q A 2)$ and heart rate; middle, pre-ejection period (PEP) and heart rate; below, left ventricular ejection time (LVET) and heart rate. Each graph shows the appropriate normal regression line with one standard deviation as given by Weissler et al. (1968) labelled by ' $W$ ', and from our own figures. 


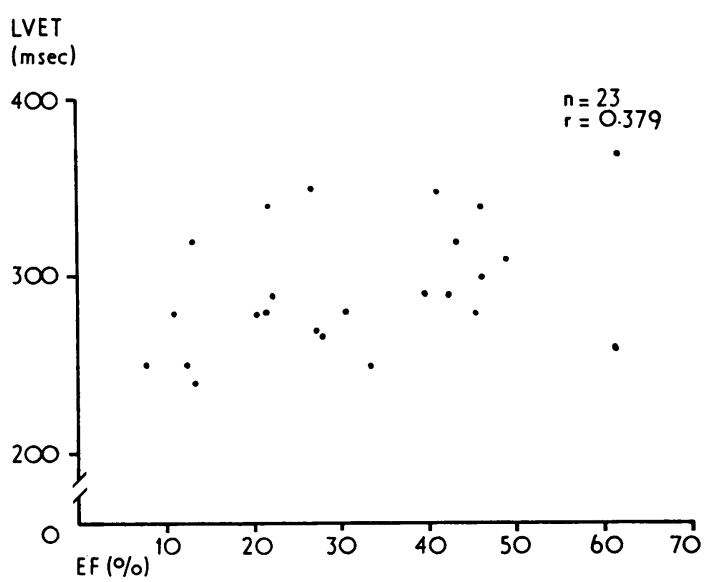

FIG. 3 Left ventricular ejection time (LVET) and ejection fraction $(E F)$.

TABLE 3 Correlation coefficients for systolic time intervals with parameters of left ventricular function

\begin{tabular}{llll}
\hline & $\begin{array}{l}d p / d t \max \\
(n=36)\end{array}$ & $\begin{array}{l}E F \\
(n=23)\end{array}$ & $\begin{array}{l}\text { Asynergy } \\
(n=23)\end{array}$ \\
\hline PEP & $\mathrm{r}=0.22 \mathrm{r}$ & 0.060 & 0.149 \\
LVET & $\mathrm{r}=0.224$ & 0.379 & 0.007 \\
QA2 & $\mathrm{r}=0.10 \mathrm{I}$ & 0.340 & 0.266 \\
\hline
\end{tabular}

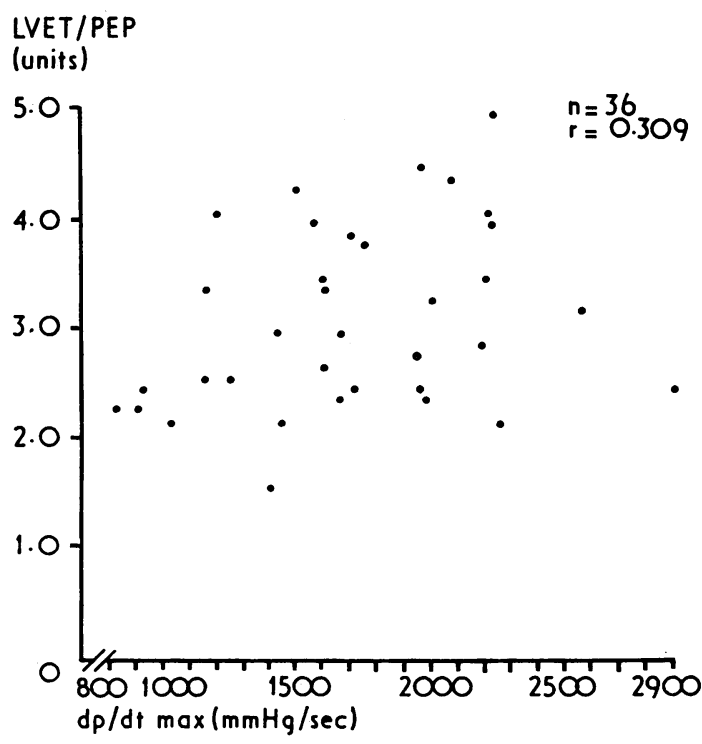

FIG. 4 LVET/PEP correlated with $d p / d t$ max. directly with the corresponding PEP. Though a relative diminution in the contribution of the ICT to the PEP appeared to occur in the presence of high values for dp/dt max, the quotient LVET/ICT offered no advantages over LVET/PEP in predicting behaviour of the pressure pulse slope or level of ejection capacity. This is in agreement with previous observations (McConahay et al., I972), and the ICT will not be further considered. The intervals $\mathrm{t}-\mathrm{dp} / \mathrm{dt}$ relax and Q-dp/dt relax were not informative either as indices of contractility or when compared to the total duration of systole or to ejection time, and will likewise not be further discussed.

The inclusion of one case of left bundle-branch block in the study did not alter significantly the overall results relative to systolic time intervals or contractility. In this patient PEP was prolonged and LVET shortened in comparison to normal values. In no patients were the coronary arteries free of disease, extensive stenoses occurring in two or more vessels for the majority of the group. In cases of previous infarction no relation between infarct localization and contractility or time interval variables could be established. Electrocardiographic and angiographic localization of lesions was in good agreement.

\section{Discussion}

This study was designed to compare contractility variables with performance and further to test the validity of applying systolic time intervals to the assessment of ventricular function in coronary artery disease. The maximal rate of change of ventricular pressure during isovolumic contraction (dp/dt max), when taken with related variables (EF, MSER), has been interpreted as an adequate index of the state of myocardial contractility (Mason, 1969; Siegel and Sonnenblick, 1963; Mason et al., I965; Krayenbühl, 1969). Patients with ischaemic heart disease may show abnormalities in contractility and ejection even in the absence of overt myocardial insufficiency or, indeed, of symptoms of angina pectoris (Malmborg, 1965; Raftery, Banks, and Oram, 1969; Chatterjee et al., 1971). Alterations of these variables could be expected to influence the pre-ejection period and the ejection phase of systole. Furthermore, changes in ventricular compliance or diastolic relaxation are common in acute (Diamond and Forrester, 1972) and chronic (Mathes and Just, I973) ischaemic heart disease. Changes of this kind tend to alter the latter part of systole as well as the velocity of contraction and ejection.

With respect to contractility and ventricular function we were able to show significant interrelation between increased dp/dt max and good ejection fraction, and between depressed $\mathrm{dp} / \mathrm{dt} \max$ and increasing 
degree of asynergic contraction. This is in agreement with previous studies which have shown uniform decrease of $\mathrm{dp} / \mathrm{dt}$, as more and more left ventricular surface area displays pathological motion, even when clinical evidence of congestive failure is minimal or absent (Klein, Herman, and Gorlin, 1967).

A particularly strong relation was obtained between ejection fraction and degree of asynergy. One patient (Case 14) showed extreme impairment of ejection fraction, 60 per cent ventricular asynergy, extensive triple vessel disease, and pronounced depression of contractility indices, yet was able to carry out a vigorous physical training programme for a prolonged period without obvious disability. That the congestive failure that eventually ensued was delayed for such a remarkable length of time was difficult to explain in view of the extent of disease present, and lends support to the observation that a severe degree of ventricular dysfunction as determined angiographically and confirmed by abnormal parameters of myocardial performance (dp/dt, EF, MSER) may be present without pronounced clinical evidence of functional embarrassment. When myocardial insufficiency does occur in coronary artery disease it may reflect the presence of a mixture of functional cardiac muscle with nonfunctional scar tissue; that is, diffuse involvement and asynergy, rather than gross fibrous scarring, may be the ultimate aetiological factor in failure (Gorlin, Klein, and Sullivan, 1967), leading even before the onset of decompensation to more severe ventricular dysfunction than a more compact, discrete lesion (Hort et al., I968).

Turning to the application of systolic time intervals for the analysis of function, we were unable to show characteristic abnormalities even in the presence of severe derangement of ventricular performance as registered by changes in contractility and ejection. In an attempt to apply systolic time intervals to the detection of functional impairment, it is important to realize that so many factors influence each interval that a direct and precise relation to any single haemodynamic event cannot be expected (McConahay et al., 1972). It has been suggested that the prolongation of the pre-ejection period observed in heart failure might be due to a diminished rate of left ventricular pressure rise during isovolumic contraction (Weissler et al., 1968, 1969). Our data did not demonstrate a significant relation between change in the pre-ejection period and diminished maximal rate of pressure rise $(\mathrm{dp} / \mathrm{dt})$. A positive correlation of these variables implies decreased $\mathrm{dp} / \mathrm{dt}$ in the presence of a steady state with respect to aortic diastolic pressure. In this connexion the augmentation of the pre-ejection period pro- longation by diastolic hypertension should be mentioned (Weissler et al., 1968; Blumberger, 1942). What might occur should dp/dt and aortic diastolic pressure fall simultaneously? Even drastically reduced levels of rate of development of $\mathrm{dp} / \mathrm{dt} \max$ would not be reflected in changes in the pre-ejection period. It has been shown in experimental myocardial infarction that a drop in arterial pressure occurs and is maintained over prolonged periods, in part assisting the functional capacity of nonischaemic areas by decreasing afterload (Hort, Just, and da Canalis, 1964). A similar mechanism may be operative in coronary artery disease, particularly where earlier infarction has occurred, shifting the chronological sequence of events before aortic valve opening to the left on the ventricular pressure curve. As a result, even where $\mathrm{dp} / \mathrm{dt}$ is compromised, the pre-ejection period need not be prolonged.

Similarly one must consider the effect of sympathetic tonus on systolic time intervals. The reflex mechanisms affecting sympathetic activity are extremely complex. Increased sympathetic excitation increases heart rate and strengthens the force of myocardial contractility. Increased heart rate alone has been shown to increase contractility (Sonnenblick, Morrow, and Williams, 1966). Associated is an increased rate of ventricular relaxation. These factors would be expected to result in both pre-ejection period and left ventricular ejection time shortening, and yet even in the failing heart, with demonstrably increased sympathetic activity, the pre-ejection and ejection periods have been found to change in opposite directions. So many factors are operative at the same time that the role played by sympathetic activity alone, without consideration of such factors as pre- and after-load, medical treatment, vagal tone, and venous pressure, may exert a varying influence on systolic time intervals in different patients at different points on the compensation scale. Under these conditions systolic time intervals would not be expected to reflect adequately a state of cardiac compensation or level of decompensation which is not already clinically obvious. It is pertinent to mention at this point that the role played in our study by the stress of the catheterization procedure was not great, as judged by the small scatter of resting heart rates. Sympathetic activity cannot, however, be overlooked in an evaluation of systolic time intervals.

Stroke volume has been demonstrated to correlate with changes in systolic time intervals, especially LVET (Weissler et al., 1968), and should likewise be discussed as a possible determinant of time relations. It is reasonable to assume that a low stroke volume with constant heart rate and peripheral resistance could occur in conjunction with pro- 
longed PEP and shortened LVET, even if no effect on total duration of systole were observed. Though mean systolic ejection rate was seen to be reduced in our patient group, decreased stroke work was not reflected in characteristic changes in either preejection period or left ventricular ejection time. The pressure-volume relation in the ischaemic heart is not static but dynamic, not only over time but at any one point in time, with variations over the entire period of diastole. Myocardial fibres which are chronically embarrassed by ischaemic disease may constantly rearrange to achieve the best, albeit a tenuous, balance between pressure, volume, and work. Under these conditions it is not surprising that the measurement of systolic time intervals, except conceivably in the overtly insufficient heart, fails to reflect true intracardiac relations. Indeed, other studies, from in part the same observers, have shown divergent results with regard to changes in systolic time intervals in relation to stroke volume (Garrard et al., 1970; Weissler et al., 1968).

Changes occurring not only during diastole but also during the relaxation phase of systole may offer an additional explanation for poor correlation of systolic time intervals with other parameters of cardiac performance. It has been shown that ventricular ejection is completed well before the end of systole. Even if the first two-thirds of systole were inscribed at a rapid rate, the relaxation phase, with onset before the end of systole, may be retarded, resulting in no net change in left ventricular ejection time or, even with concurrent changes in pre-ejection time, in the total duration of systole. We have shown a definite decrease in the rate of change of left ventricular pressure $(\mathrm{dp} / \mathrm{dt})$ from the phase of isovolumic contraction to that of isovolumic relaxation in well over half of our patient group, and yet ejection time and total electromechanical systole did not significantly deviate from normal.

A consideration of the therapeutic regimen is also important. Digitalis, for example, improves cardiac contraction and increases stroke volume and cardiac output. Blumberger (1942) showed that the most definitive effect of digitalis was on the pre-ejection period, and went so far as to recommend the evaluation of changes in the pre-ejection period before and after digitalization as an index of successful therapy. Other observers have reported contradictory findings with regard to the effects of digitalis administration on the total duration of systole (Weissler et al., 1969, I965). It must be recalled that digitalis is frequently given in combination with diuretic agents, and changes in blood volume with varying degrees of diuresis would also play a part in the time required for systolic contraction and relaxation.
Finally, not only normal pre-ejection periods but no significant changes in other time intervals have been observed in acute myocardial infarction (Samson, 1970; Halpern et al., 1969), even when paradoxical systolic pulsations present over the praecordium would imply an extreme reduction in contractility, and the greater use of the contractile element, requiring more time for the development of pressure within the left ventricle.

We have attempted to show that the determinants of systolic time intervals are complex and varied, and that in consequence application of systolic time intervals to the momentary haemodynamic status can be made only with caution. The time required for the accomplishment of intracardiac events, each dependent on many variables, is naturally predisposed to variance. Abnormal time relations may adequately reflect that stage in the disease process at which compensatory mechanisms have been exhausted, but not the indices of function as long as the cardiovascular reserve is sufficient to prevent manifest failure. Changes over a period of time may be useful in the ongoing evaluation of the individual patient, but alterations in the time intervals at an individual examination provide only rough approximations of patient status. From our observations it is doubtful whether consideration of systolic time intervals, either internally or at the bedside, offer a reliable index of cardiac function in the damaged but compensated ischaemic heart.

\section{References}

Aronow, W. S., Bowyer, A. F., and Kaplan, M. A. (197I). External isovolumic contraction times and left ventricular ejection time/external isovolumic contraction time ratios at rest and after exercise in coronary heart disease. Circulation, 43, 59.

Blumberger, K. (1942). Die Untersuchung der Dynamik des Herzens beim Menschen. Ergebnisse der inneren Medizin und Kinderheilkunde, 62, 424.

Chatterjee, K., Sacoor, M., Sutton, G. C., and Miller, G. A. H. (1971). Angiographic assessment of left ventricular function in patients with ischaemic heart disease without clinical heart failure. British Heart fournal, 33, 559.

Diamond, G., and Forrester, J. S. (1972). Effect of coronary artery disease and acute myocardial infarction on left ventricular compliance in man. Circulation, 45, II.

Dodge, H. T., Sandler, H., Ballew, D. W., and Lord, J. D. (1960). The use of biplane angiocardiography for the measurement of left ventricular volume in man. American Heart fournal, 60, 762.

Garrard, C. L., Jr., Weissler, A. M., and Dodge, H. T. (1970). Relationship of alterations in systolic time intervals to ejection fraction in patients with cardiac disease. Circulation, 42, 455.

Gorlin, R., Klein, M. D., and Sullivan, J. M. (1967). Prospective correlative study of ventricular aneurysm; mechanistic concept and clinical recognition. American fournal of Medicine, 42, 512. 
Halpern, B. L., Hodges, M., Dagenais, G. R., and Friesinger, G. C. (I969). Left ventricular pre-ejection period and ejection time in patients with acute myocardial infarction. Circulation, 40, Suppl. III, I00.

Hort, W., Just, H., and da Canalis, S. (1964). Untersuchungen bei ausgedehntem experimentellen Infarkt der linken Kammerwand. Verhandlungen der Deutschen Gesellschaft für Kreislaufforschung, 30, 288.

Hort, W., Just, H., Fischer, K., and Lüth, G. (1968). Infarktmuster in menschlichen Herzen. Virchows Archiv für pathologische Anatomie, 345, 45.

Klein, M. D., Herman, M. V., and Gorlin, R. (1967). A hemodynamic study of left ventricular aneurysm. Circulation, 35, 614.

Krayenbühl, H. (1969). Die Dynamik und Kontraktilitaet des linken Ventrikels. Bibliotheca Cardiologica, 23. Karger, Basel.

McConahay, D. R., Martin, C. M., and Cheitlin, M. D. (1972). Resting and exercise systolic time intervals: correlations with ventricular performance in patients with coronary artery disease. Circulation, 45, 592.

Malmborg, R. O. (1965). A clinical and hemodynamic analysis of factors limiting the cardiac performance in patients with coronary heart disease. Acta Medica Scandinavica, 177, Suppl. 426.

Mason, D. T. (1969). Usefulness and limitations of the rate of rise of intraventricular pressure $(\mathrm{dp} / \mathrm{dt})$ in the evaluation of myocardial contractility in man. American fournal of Cardiology, 23, 516.

Mason, D. T., Sonnenblick, E. H., Ross, J., Jr., Covell, J. W., and Braunwald, E. (1965). Time to peak dp/dt: a useful measurement for evaluating the contractile state of the human heart. Circulation, 32, Suppl. 2, I45.

Mathes, P., and Just, H. (1973). Die elastischen Eigenschaften der linken Herzkammer bei Koronarkranken. Klinische Wochenschrift. In preparation.

Metzger, C. C., Chough, C. B., Kroetz, F. W., and Leonard, J. J. (1970). True isovolumic contraction time: its correlation with two external indexes of ventricular performance. American fournal of Cardiology, 25, 434.

Raftery, E. B., Banks, D., and Oram, S. (1969). Left ventricular function in ischaemic heart disease (abstract). British Heart fournal, 31, 793.

Samson, R. (1970). Changes in systolic time intervals in acute myocardial infarction. British Heart fournal, 32, 839.

Siegel, J. H., and Sonnenblick, E. H. (1963). Isometric timetension relationships as an index of myocardial contractility. Circulation Research, 12, 597.

Sonnenblick, E. H., Morrow, A. G., and Williams, J. F., Jr. (1966). Effects of heart rate on the dynamics of force development in the intact human ventricle. Circulation, 33, 945.

Weissler, A. M., Harris, W. S., and Schoenfeld, C. D. (1968). Systolic time intervals in heart failure in man. Circulation, 37, 149.

Weissler, A. M., Harris, W. S., and Schoenfeld, C. D. (1969). Bedside technics for the evaluation of ventricular function in man. American fournal of Cardiology, 23, 577.

Weissler, A. M., Kamen, A. R., Bornstein, R. S., Schoenfeld, C. D., and Cohen, S. (1965). The effect of deslanoside on the duration of the phases of ventricular systole in man. American fournal of Cardiology, 15, 153.

Requests for reprints to Professor H. G. Just, Department of Cardiology, II Medizinische Universitätsklinik und Poliklinik Mainz, Langenbeckstr. I, D-65 Mainz I, Germany. 